\title{
Dendritic Growth and Spread of Electrochemical Research in India
}

\author{
N KALAISELVI ${ }^{1}$ and VIJAYAMOHANAN K PILLAI ${ }^{2, *}$ \\ ${ }^{1}$ CSIR-Central Electrochemical Research Institute, Karaikudi 630 003, India \\ ${ }^{2}$ IISER-Tirupati
}

(Received on 03 March 2019; Revised on 25 May 2019; Accepted on 05 June 2019)

\begin{abstract}
Electrochemistry Research has undergone a rapid growth in India during the last decade due to several reasons. Ambitious renewable energy targets with implicit need for storage systems, More focused attention on Electric Mobility due to climate related commitments, enhanced public interest in environmental remediation and effluent treatments, expanding research-infrastructure in many IISERs, new IITs, NITs and other private and public universities, availability of diverse types of size and shape selective materials and many other such reasons are responsible. Several laboratories are doing well in developing new materials for applications in batteries, biosensors, fuel cells etc., despite barriers for industrial deployment. This article examines the status of research in electrochemistry and contiguous areas providing a cursory glance of some of the recent excitements.
\end{abstract}

Keywords: Electrochemistry; Energy Storage; Li-ion Batteries; Fuel Cells; Electroplating; Corrosion Prevention; Electrosynthesis; Electrochemical Sensors

\section{Introduction}

Electrochemical science and technology represents itself as an indispensable option to solve many current global challenges for which e-mobility and carbon dioxide sequestration are the typical examples. With the growing concern for the implementation of relatively greener technologies and to fulfill the prioritized mandate of the global community to ensure reduction of carbon footprint, a paradigm shift towards electrochemical technologies has happened recently in India. Accordingly, the country in the last few decades has witnessed many fruitful technological outcomes due to tremendous research efforts in the field of electrochemistry involving various interdisciplinary approaches. In particular, areas like renewable and bio-energy, water and affordable health care, cleaner and greener environment have seen many innovative initiatives involving many new applications of electrochemical science and technology.

Starting from the lithium-ion cells for mobile phones and laptops to the health diagnostic strips of today, electrochemical research has been viewed as a greener and sustainable technological platform by researchers across the globe. As a result, this interdisciplinary area has been widely studied, practiced and nurtured globally to accomplish customized strategies to solve common issues of the society, involving multidisciplinary scientists and engineers as one team. There were times when country like India had rarely spotted electrochemical researchers with an exception of Central Electrochemical Research Institute (CECRI), Indian Institute of Science (IISc.) and few Indian Institute of Technologies (IITs) and very few other institutions that could function as an electrochemical solution provider to past societal as well as fundamental issues. However, with the multifaceted and fast spreading electrochemical technology outbreaks in processes, instrumentation and appliances, many leading research organizations, industries, academia and technology crucibles of public sector units also started dedicated research wings to promote electrochemical research as an end-to-end solution provider to many challenging and unsolved issues of modern life style. In short, electrochemistry offers practically viable and sustainable solutions to most of 
the global problems of to-day, by way of exploiting the advantages of modern electrochemistry and the technological outcomes associated thereof (Gladysz and Michel, 1990). Today's e-society demands multifunctional materials and multi-tasking teams human (often also with machine-intelligence), capable of addressing multifarious challenges not through multiple technologies, but by exploiting a single and globally accepted end-to-end solution. Towards this direction, modern electrochemistry with the advent of single cell electrochemistry, sophisticated in-situ analyzers, smart sensors, handheld devices and mobile apps for real time analysis, in-vivo and in-vitro bio medical trails, neurotransmitter governed health care, state-of-health monitoring through techi-ornaments and e-fabrics, etc. in synergy have created milestones in the life style as well as significant achievements in strategic sector (Uslu et al., 2011). In particular, the confluence of nanotechnology, biotechnology and electrochemistry driven advancements have offered unimaginable scopes in ensuring affordable livelihood, apart from leaving behind possibly a green earth for the upcoming generations too. In this backdrop, present article deals with the recent advancements and technologically vibrant innovations realized through electrochemical science and technology, which are believed as game changers in combating the socio economically and environmentally important critical issues in a non-exhaustive manner.

Quite different from the conventional reviews, this document covers a survey of viable electrochemical strategies being adopted to solve certain contemporary problems in Indian institutions and research organizations. Because, unlike the yester years, the growing awareness and the widespread applications being demonstrated by electrochemical researchers and scientists in handling the changing demands and challenges of our modern life style, students and academicians express a strong interest to understand and to practice electrochemical techniques especially to acquire thermodynamic and kinetic information often in operando or coupled with in situ spectroscopies. Since many great technological accomplishments have taken place recently, taking stock of institutions involved in electrochemical R\&D along with their contributions and the recently realized impact making electrochemical technologies or processes in meeting out the requirements assumes importance. We also discuss the current status of electrochemical research of this nation in detail, trying to approach as a vibrant and ever growing interdisciplinary area with its inexorably deep roots in new materials for all types of applications covering energy, environment and water.

\section{Electrochemistry Landscape}

Electrochemistry, as one of the branches of physical chemistry deals with the electrochemical reactions and processes occurring at the electrode-electrolyte or electrolyte-electrolyte interface. One can understand the importance of electrochemistry through its application in our daily life, starting with batteries in our mobiles and torches to many domestic and smart appliances apart from many other spontaneous physiological processes taking place in our body that depend on electrified interfaces and electrochemical processes (Bard and Faulkner, 2000). Electrochemical processes are critically used in industries for the production of chlorine, alkalis, a range of oxidizing agents, fluorine and organo-fluoro compounds. Using electrochemical techniques, precious metal requirements of this nation including aluminium, magnesium, sodium, lithium, beryllium, tantalum, titanium, zinc, and copper could be met out indigenously although huge demand is fulfilled by imports. Of late, hydrogen, the green and alternative fuel, is produced by the electrolysis of water. Similarly, protective and decorative electroplating finds major application towards the development of electric automobile sector of today. The rapidly increasing demand for independent sources of electric power in industry, space exploration, modern household appliances and our recent addition to smart and sleek e-gadgets stimulate the search for new electrochemical systems with enhanced efficiency, power capacity and safety. Similarly, certain most important biological processes, viz., assimilation and use of food energy, transmission of the nervous impulse, usage of health bands/strips and the detection of visual image are impossible without the electrochemical links, which in turn are related to the functioning of biological membranes. In short, appreciable progress has been made in this century in understanding the fundamentals as well as the possible areas of application of electrochemical processes across the globe. Indian researchers are also influenced in this regard and India has contributed significantly both in terms of exploration as well as 
deployment of indigenous electrochemical technologies.

\section{Energy: Electrochemical Energy Generation, Conversion and Storage}

\section{Generation}

India ranks at the top along with the U.S. Japan and the U.K. in developing fuel cell technology for realtime applications, and in particular, the Council of Scientific and Industrial Research (CSIR) is engaged in developing indigenous Polymer Electrolyte Membrane Fuel Cells (PEMFC), Direct Methanol Fuel Cells (DMFCs) and Microbial Fuel cells (MFCs) at materials, component, sub-assembly, stack and at system level. Over the last few years, CSIR has developed several fuel cell stacks, demonstrated for performance and transferred the technology to end users for domestic as well as strategic applications. The key achievements include $\mathrm{H}_{2}$ /air $3 \mathrm{~kW}$ water cooled PEMFC systems for stationary and telecommunication applications of Ms. Reliance, $\mathrm{H}_{2} /$ air $1 \mathrm{~kW}$ air cooled PEMFC stack for hydrogen removal, delivered to IGCAR, Kalpakkam and 4.5 kW HT PEMFC stack for automotive application that has been transferred to M/s. TVS Auto, Hosur. However, several challenges do remain till date for the economical deployment and further work is essential on the development of noble metal free electrocatalyst, light weight composite graphite bipolar plates with improved stability and self-humidified Nafion based composite membranes to make the stacks more cheaper (MNRE Report, 2016).

Other than CSIR labs and few IITs, Advanced Research Centre, International for Powder Metallurgy and New Materials (ARCI), Naval Materials

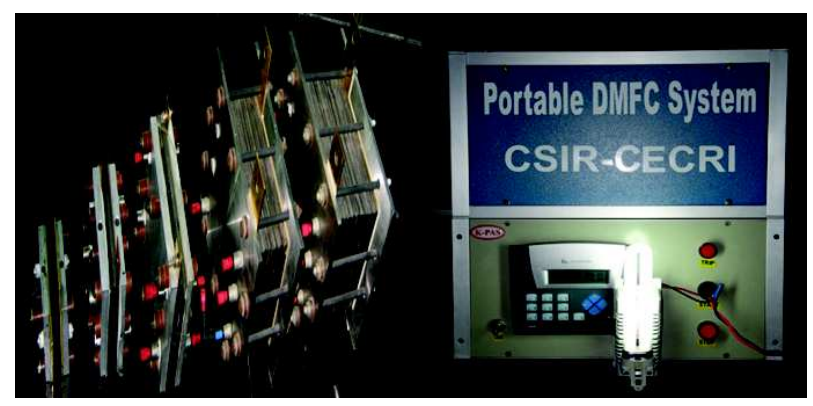

Fig. 1: PEMFC stack assembly of various capacities; an example of a $45 \mathrm{~W}$ self-sustained DMFC Module is shown here
Research Laboratory (NMRL) and some universities also are involved in the development of fuel cells focusing more on electrocatalyst materials and membranes. Southern Petrochemical Industries Corporation (SPIC) science foundation has developed many 3-5 kW PEM fuel cell stacks and hydrogen-air PEM fuel cell stacks for battery hybrid vehicles (12 seater van) and uninterrupted power supply (UPS). Researchers at the Indian Institute of Science Education and Research (IISER) in Pune developed a fuel exhaling fuel cell (FEFC) that not only generates electricity but also "exhales" hydrogen, which is a value added hydrogen-oxygen fuel cell technology, since it offers the possibility of designing a complete closed-loop fuel cell without storing hydrogen externally but by generating it in-situ. It is important to mention here that the Indian Railways' fuel arm is also being experimented with hydrogen-powered fuel cells on a pilot basis (MNRE Report, 2016).

More importantly, the Society of Indian Automobile Manufacturers (SIAM) has called for developing the fuel cell technology to meet the Government's target of implementation of e-mobility by 2030, a mandate as per the requirements of COP 21 and COP 22 agreements. CSIR-CECRI is inexorably working on the generation of hydrogen by Proton Exchange Membrane (PEM) based water electrolysis, photochemical oxidation of water using molecular catalysis and water oxidation by functional electrocatalysts and novel composite electrolytes. Water electrolysis by PEM concept for onsite hydrogen production is preferred, because of its simplicity, versatility and high purity. Beginning with the development of $100 \mathrm{~W}\left(0.02 \mathrm{~m}^{3} / \mathrm{hr}\right)$ PEM-based hydrogen generator, CECRI has developed technologies to few companies on $25 \mathrm{~kW}\left(5 \mathrm{~m}^{3} / \mathrm{hr}\right)$ PEM-based hydrogen generator that has the capacity to generate $5 \mathrm{Nm}^{3}$ of fuel cell grade hydrogen per hour. In addition, development of functional electrocatalysts and novel composite electrolytes for hydrogen generation from water using photovoltaic arrays is being attempted by many national laboratories in the recent times. New crystalline organic polymers upon usage with electrocatalysts are found to tilt the kinetics favorably to split water and produce hydrogen and oxygen, which is quite interesting. It is important to mention here that researchers at IISER, Kolkata have developed a proof-of-concept "paperelectrolyzer" by transforming ubiquitous substrates 
into highly efficient and flexible electrodes for water splitting (Sahasrabudhe et al., 2018) and start-ups based on many such innovations are expected in the coming years.

Production of electrical power from food wastes using microbial fuel cell assembly through an efficient waste-to-wealth concept is one of the emerging topics today. In order to facilitate this in a cost-effective manner efficient design of microbial fuel cells (MFCs) that produces electric energy is essential and in this regard, usage of waste from landfill has also been proposed recently. In line with this, treatment of wastewater with concurrent resource recovery and bio-electricity generation has been demonstrated by CSIR-IICT in a $100 \mathrm{~L}$ semi-pilot plant, which is noteworthy. Of late, many start-up companies are looking forward to implement microbial fuel cell technology. Development of a biofuel cell for biomedical applications, apart from the modification of solid electrolyte for direct alcohol fuel cell and for high temperature applications is also receiving attention from researchers with diverse back-ground.

\section{Energy Conversion}

While energy generation is carried out extensively using more innovative materials and processes, it is equally important to concentrate on the development of energy efficient conversion coupled with storage techniques, without which the ultimate goal of self sufficiency in the field of energy could not be accomplished. In this regard, dye sensitized solar cells (DSSC), solar photovoltaic (SPV), organic photovoltaic (OPV) and silicon solar cells (SSC) play a pivotal role to convert solar energy in to electricity for further applications. Even though the deployment of dyes for DSSC is being studied since 1985, a successful demonstration of the prototype device was exhibited for the first time from EPFL, Switzerland (O'Regan and Grätzel, 1991) several decades ago. In India, research in the area of solar energy harvesting has been undertaken rigorously in the past 5 years, with a focus to develop lab level solar cell fabrication technologies, including improved silicon based solar cells, organic solar cells, thin film solar cells, dyesensitized solar cells and solar-thermal devices. CSIR labs such as Indian Institute of Chemical Technology (IICT), National Institute for Interdisciplinary Sciences (NIIST), National Chemical Laboratory (NCL) and
National Physical Laboratory(NPL) demonstrate reproducible cell efficiency behavior closer to international standards on their lab-scale cell architectures. The major activities in DSSC and related solar cell research areas have been nationally coordinated under the Technologies and Products for Solar Energy Utilization through Networks (TAPSUN) program of CSIR and SERI of DST. MNRE funded few other projects developed nanostructured metal oxides, sensitizers, redox electrolytes etc., for optimized lab-level devices and large area modules, while several individual and collaborative research proposals are being funded by DST-SERI. At present, both CSIR-NIIST and CSIR-IICT have achieved an efficiency of $10 \%$ at the cell level for certain unique combination of materials. It is worth mentioning here that the goal of CSIR labs is the development of indigenous DSSC technology for Self Powered Internet of Thing (IoT) smart solutions in tune with the objectives of "Make in India" scheme.

India stands at a solar installed capacity of nearly $21.65 \mathrm{GW}$ as on March 2018. Recently, photovoltaic based electricity generation cost has been brought down from the initial value of INR 17/unit to about INR 6.5/unit today, due to the tremendous efforts of our researchers towards the development of PV from various institutions. Further, CSIR institutes including NCL, NPL, Central Leather Research Institute (CLRI), Institute of Minerals and Materials Technology (IMMT) and NIIST are investing tremendous efforts in developing large area, stable and efficient perovskite solar cells. Recently, researchers from Pune's Indian Institute of Science Education and Research (IISER) have successfully produced a stable, high-efficiency $(10.8 \%)$, allinorganic perovskite nanocrystal solar cells (Swarnkar et al., 2016). Towards this direction, Solar Energy Research Institute for India and the United States (co-led by the Indian Institute of Science (IISc)Bangalore, India, and the National Renewable Energy Laboratory (NREL), Golden, Colorado, USA) have jointly conducted the SERIIUS program to accelerate the development of solar electric technologies by lowering the cost per watt of photovoltaics (PV). Further, a team of researchers from Britain and India (IIT Delhi, NPL Delhi, CSIR Hyderabad, IISER Pune, and IIT Kanpur) has started Strategic University Network to Revolutionize Indian Solar Energy (SUNRISE) project to develop next-generation 
photovoltaics (PVs) in the country with the aim of providing low-cost printed PVs and tandem solar cells for use in off-grid conditions. More importantly, the three state-owned Indian research bodies, viz., Indian Railways Organisation for Alternate Fuels (IROAF), Indian Institute of Petroleum (IIP) Dehradun and National Institute of Solar Energy (NISE) are working currently to develop solar-assisted biomass production also.

\section{Energy Storage}

As far as research and development on lithium ion batteries is concerned, CSIR labs are marching towards the development of the country's first indigenous technology of lithium-ion cells. It is important to mention here that by using skills at various CSIR laboratories, indigenously developed 3.6 V, 650 mAh $18650 \mathrm{Li}$-ion cells using proprietary electrode materials have successfully been developed specifically using anodes from NPL and separators from Central Glass and Ceramic Research Institute (CGCRI). Basically, there are three developmental/ pilot scale lithium-ion battery production facilities in the country. i.e., in addition to CSIR-CECRI's patented LIB electrode materials and the fabrication facility at CECRI Madras centre at Taramani, Chennai to make 2 Ah pouch and 18650 lithium-ion batteries, Vikram Sarabhai Space Centre (VSSC), Trivandrum has a larger facility to produce space quality lithium-ion batteries in the range of 5-100 Ah (Sampath et al., 2016). ARCI at Chennai has the facility to make automotive lithium-ion batteries of 10-100 Ah level apart from its capability to produce large scale $(1 \mathrm{~kg} /$ $\mathrm{hr}$ ) indigenous electrode materials. IIT, Mumbai (Department of Energy) also has facilities to process smaller version of lithium-ion cells. Research institutions like IIT-Bombay, Madras, Delhi, Kharagpur and IISc., Bangalore are developing the electrode materials for lithium ion batteries while excellent modelling and simulations studies are being carried out on various aspects like thermal runaway, failure modes, safety issues, life-limiting factors in IITs (specifically Bombay, Kanpur and Kharagpur) and also in Center for Study of Science, Technology and Policy (CSTEP). As far as the public sector is concerned, Indian Oil Corporation Ltd. (IOCL), Hindustan Petroleum Corporation Ltd. (HPCL) and Bharat Heavy Electrical Ltd. (BHEL) are working on the development of lithium ion battery technology.
Apart from lithium ion battery development, economically viable next generation storage alternatives like lithium-sulfur, sodium-ion, redox flow and metal-air systems are given prime importance in the lab scale research and development, with a view to promote a practically viable technology for realtime applications in the near future (Sampath et al., 2016).

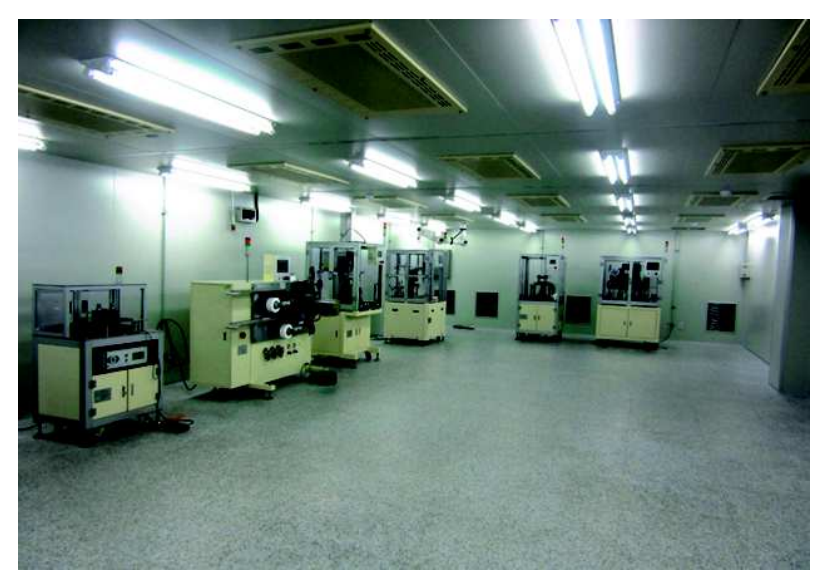

Fig. 2: Dry Room Facility for manufacturing Li-ion batteries in CSIR-CECRI

It is well known that CSIR-CECRI is one of the pioneering institutes in developing conventional as well as valve regulated lead acid (VRLA) batteries. Besides the transfer of know-how for more than 30 licenses all over the country in lead acid battery manufacturing technology in the past, CECRI works in collaboration with TVS Motors, Kinetic engineering, MNRE and Reliance Industries to qualify lead acid batteries for electric vehicle (EV) applications. The NABL accredited CSIR-BPTEC (Battery performance testing and evaluation centre) is a unique facility for assisting battery industries in quality management. Till now, more than 200 industries including Exide Industries, Amararaja Batteries, NED Energy, Mahindra Reva, Microtek, Amco, etc., have benefitted out of this facility. Table 1 summarizes the R\&D activities of lithium/energy storage assembly in the country (Sampath et al., 2016).

With regard to redox flow batteries, meant for large scale storage applications, CSIR labs concentrate on the development of $\mathrm{Zn}-\mathrm{Br}_{2}$ redox flow systems and the Indian Institute of Technology-Madras and 
the Indian Institute of Technology-Delhi, Rajiv Gandhi Institute of Petroleum Technology, Indian Institute of Science and Indian Institute of Engineering Science and Technology (IIEST), Shibpur, Howrah are working for the development of vanadium based redox flow batteries. India's expertise to demonstrate supercapacitor packs in cylindrical as well as in pouch configuration to glow LEDs needs to be extended to develop flexible, bendable and stretchable forms of storage devices with a team of dedicated researchers across this nation.

Table 1: Storage batteries related research in India; full forms of all abbreviations are explained in the text (However, please not these are representative examples and not an exhaustive list)

\begin{tabular}{|c|c|}
\hline Organizations & Theme of research \\
\hline a) ARCI & Lithium batteries, fuel cells and supercapcitors \\
\hline b) ISRO & Lithium batteries and supercapcitors \\
\hline c) NISE & Renewable energy - Batteries for SPV \\
\hline d) IITs & $\begin{array}{l}\text { Electrodes and electrolytes for rechargeable alkali } \\
\text { metal batteries }\end{array}$ \\
\hline $\begin{array}{l}\text { e) IISc., } \\
\text { Bangalore }\end{array}$ & $\begin{array}{l}\text { Electrodes for lithium-ion / lithium-air batteries } \\
\text { and lead based supercapacitors }\end{array}$ \\
\hline $\begin{array}{l}\text { f) CSIR labs } \\
\text { (CECRI, NCL, } \\
\text { NPL, CGCRI, }\end{array}$ & $\begin{array}{l}\text { Advanced lead-acid batteries (NABL accredited } \\
\text { battery testing), redox flow batteries, fuel cells, } \\
\text { lithium-ion batteries, sodium-ion batteries, IICT) } \\
\text { lithium-sulfur and lithium-air batteries and } \\
\text { supercapacitors }\end{array}$ \\
\hline \multicolumn{2}{|l|}{ Public Sector: } \\
\hline IOCL & Lithium batteries \\
\hline HPCL & Redox flow batteries \\
\hline CSTEP & $\begin{array}{l}\text { Lead and lithium batteries related modeling and } \\
\text { simulation studies }\end{array}$ \\
\hline BHEL & Lithium batteries \\
\hline \multicolumn{2}{|c|}{ Electrochemical Industries: } \\
\hline $\begin{array}{l}\text { High energy } \\
\text { batteries }\end{array}$ & $\begin{array}{l}\text { Lead acid and Ni-MH batteries; interested to } \\
\text { initiate lithium batteries }\end{array}$ \\
\hline $\begin{array}{l}\text { Amararaja } \\
\text { Batteries }\end{array}$ & Lead acid, Ni-MH and lithium-ion batteries \\
\hline Exide Batteries & Lead acid batteries \\
\hline $\begin{array}{l}\text { High Energy } \\
\text { Batteries }\end{array}$ & $\begin{array}{l}\text { Lead acid batteries, silver-zinc batteries, sea } \\
\text { water activated and other customized batteries } \\
\text { for defense applications }\end{array}$ \\
\hline
\end{tabular}

\section{Electrocatalysis}

Electrocatalysis is a special field in electrochemistry that has gained phenomenal growth after the late eighties due to the application of new hybrid techniques for precise characterization of surfaces and also synthetic capability coupled with computation and modelling. In particular, the application of new concepts of electrocatalysis for industrial, medical and bio medical electrochemical processes invite the attention of researchers with science and engineering background. Herein, novel functional materials and electrocatalysts for a wide range of applications including biosensors, chemical sensors, diagnostic tools for lipids, proteins and metal ions, composite materials for engineering applications, bio-mimetics, electrochemical systems for the recovery and detection of precious metals along with modeling studies on electrochemical processes and reactors receive paramount importance. The approach to accomplish such objectives requires monitoring of changes in the electrochemical parameters like current, potential and impedance. In addition, alterations in chemi-luminescence, hydrophobichydrophilic nature, electro-chromic properties may also be required to be monitored.

As far as fundamental studies in electrochemistry is concerned, emerging field of nano scale electro catalysis, wherein electrochemical generation of atomic metal clusters and their (spectro-) electrochemistry, surface electrochemistry of single metal nano crystals and nano scale segregation on bimetallic electro catalytic surfaces receive greater attention sometimes using in situ and in operando electrochemical techniques. In addition, electrodeelectrolyte interface and the charge transfer across the semiconductor/electrolyte interfaces are also being studied in order to recommend and design the guidelines for selective electro catalysis and reactivity tuning to engineer electrochemical interfaces, which influences the reaction selectivity. Apart from this, several well-known interactions viz. electrostatic, hydrophobic, covalent bonding and anchoring of nanoparticles are studied for enzyme immobilization and its activity on these modified surfaces. Further, engineering of electrochemical interfaces with various size and shape tuned nanomaterials has helped to enhance the eletrocatalytic activity for Oxygen Evolution Reaction(OER), Oxygen Reduction Reaction (ORR), Hydrogen Evolution Reaction(HER) and Hydrogen Oxidation Reaction (HOR) (Anantharaj et al., 2018) with respect to Precision and correctness in the evaluation of electrocatalytic 
water splitting. Apart from CSIR labs, many academic institutions like IITs also focus on the interfacial phenomena by integrating the experimental and theoretical electrochemistry. In addition, they develop efficient catalysts for OER and HER in water electrolyser system. Similarly, researchers at IISER Pune are actively involved in probing the complex phenomena at the electrode/electrolyte interface by a range of electrochemical, microscopic and spectroscopic techniques. Towards this direction, CECRI has established electrochemiluminescence spectroscopy (ECL) as a unique facility in India, made available through a cross cluster MULTIFUN project (Raju et al., 2017).

\section{Bio Electrochemistry and Human Health Diagnostics}

Development of simple, cost-effective and efficient sensors and catalytic materials to identify biologically relevant molecules like alcohols and sugars by monitoring their electrochemical oxidation processes using chemically modified semiconductor electrodes is a newer approach in extending electrochemical techniques to ensure affordable health care. In an attempt to develop electrochemical bio-sensors for the management of diabetes and its complications, sensors for glycated Albumin, glycated Haemoglobin, Microalbminuria, Albumin to Creatinin Ratio (ACR) assume importance. A start-up to be incubated at IISc, Bangalore will be implementing this technology soon. Table 2 displays various organizations involved in developing electrochemical type of bio-sensors, finding exciting applications in biomedical field. Furthermore, Ion Selective Field Effect Transistor(ISFET) platform, as a part of sensors, fiber optic based biosensors for proteins and bacteria, cost effective E. coli sensor which can sense about $100 \mathrm{cfu} / \mathrm{ml}$ (cfu indicates colony forming unit) are few other attempts wherein encouraging results are obtained by researchers. Towards this direction, CECRI has developed nonenzymatic hemoglobinA1c (HbA1c) sensor for early diagnosis of diabetics as early as 2000 and transferred the technology to Piramal Health Care, although few challenges remain for commerciliazation (Manohar et al., 2010). In addition, a farmer-friendly hand-held NPK sensor kit has been recently developed and demonstrated by CECRI, which in turn is an evidence of multifunctional applications of electrochemical sensors.

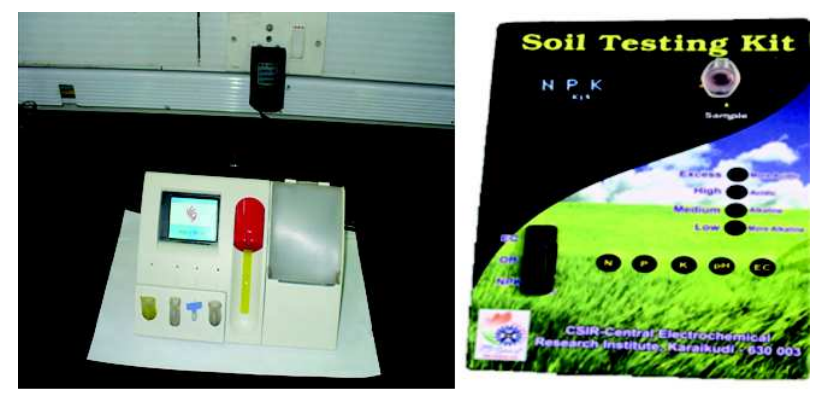

Fig. 3: HbA1c sensor laboratory prototype and Farmerfriendly NPK sensor kit developed by CSIR-CECRI

NIIST is involved in the development of inorganic materials and polymers for applications in molecular sensing, imaging and diagnostics while Central Salt and Marine Chemicals Research Institute (CSMCRI) has developed disposable plastic chip reference electrodes (PCRE) to detect heavy and toxic metal ions in water. Similarly, Central Mechanical Engineering Research Institute (CMERI) has developed and demonstrated a disposable phenolic strip and sensor kit for the detection of catechol. Prototype model of electro phoretic sensor for rapid and multiplexed detection of food-borne pathogens by CGCRI is under development.

Table 2: Electrochemical and biosensor research in India: few representative examples

\begin{tabular}{|c|c|}
\hline Organizations & Theme of research \\
\hline $\begin{array}{l}\text { IITs } \\
\text { CSIR Labs } \\
\text { (NIIST, } \\
\text { CSMCRI, } \\
\text { NPL, NCL } \\
\text { CMERI, } \\
\text { CECRI, } \\
\text { CGCRI) }\end{array}$ & $\begin{array}{l}\text { Sensors for neurotransmitters and various other } \\
\text { bio-analytes, E.coli, BOD and COD sensors } \\
\text { MEMS sensor for molecular imaging, disposable } \\
\text { electrodes for water purification, electrophoretic } \\
\text { sensor for food borne pathogens, NPK sensor } \\
\text { for formers and HbA1C sensor for diabetes }\end{array}$ \\
\hline $\begin{array}{l}\text { Indian Univer- } \\
\text { sities (VIT, } \\
\text { Madurai } \\
\text { Kamaraj } \\
\text { University, } \\
\text { BHU) IISc, } \\
\text { Bangalore }\end{array}$ & $\begin{array}{l}\text { Electrochemical and bio-electrochemical sensors } \\
\text { chemo sensors and biomedical applications } \\
\text { Electrochemical bio sensors for bio-analytes and } \\
\text { also for diabetes management }\end{array}$ \\
\hline
\end{tabular}

Work on impedance-based biosensors for the detection of pathogens and food toxins is ongoing at the Bengal Engineering and Science University also. Using low cost screen printing methods, they have developed a prototype of a macroporous silicon device, 
interfaced with an electronic readout, for sensitive detection of E.coli in blood. Advent of microelectromechanical sytems (MEMS) technology results in miniature sensors, with a possibility of integration into point of care systems. A study on the highly sensitive MEMS sensor, working in the resonant mode, is ongoing at the IITs in Bombay and Madras.

\section{Corrosion Based Health Assessment of Structures}

Electrochemistry addresses not only human health care, but also the health assessment and the subsequent maintenance of material wealth of this nation, which in turn testimonies the wide range of applications of electrochemical technologies to ensure greener and cleaner environment. Such attempts include bio-electrokinetics, electro-bioremediation, cathodic protection, paints and surface/decorative coatings, concrete corrosion and failure analysis. CECRI plays a key role in the field of corrosion which in turn has led to the development of a number of anti-corrosion products and processes. Subsequent to the ever first attempt to design the corrosion map of India by CECRI, several instrumentation designs, techniques, and sensors have been developed to monitor the health of bridges and structures at various parts of this country. It is important to mention here that a wide variety of corrosion problems including the monitoring of the health of nuclear reactors, development of corrosion resistant concrete, novel cathodic and anodic inhibitors, protection for concrete sensitive rebars etc., by electrochemical researchers receive strategic as well as industrial importance. For example, corrosion monitoring sensors installed by CECRI scientists in Koodankulam Nuclear Power plant (KKNPP) endorses the significance of electrochemistry in fulfilling the strategic requirements of this nation. Protection of Pamban Bridge using CECRI's cement polymer composite coating, maintenance of Thrivalluvar statue situated in the mid sea at Kanyakumari against corrosion and the KKNPP's implementation of installation of corrosion monitoring sensors that has been made as a mandate in the upcoming units of KKNPP are the live and nationally important accomplishments realized using electrochemical techniques by core electrochemists.

In addition, special protective superhydrophobic paints, self-healing coatings and a variety of

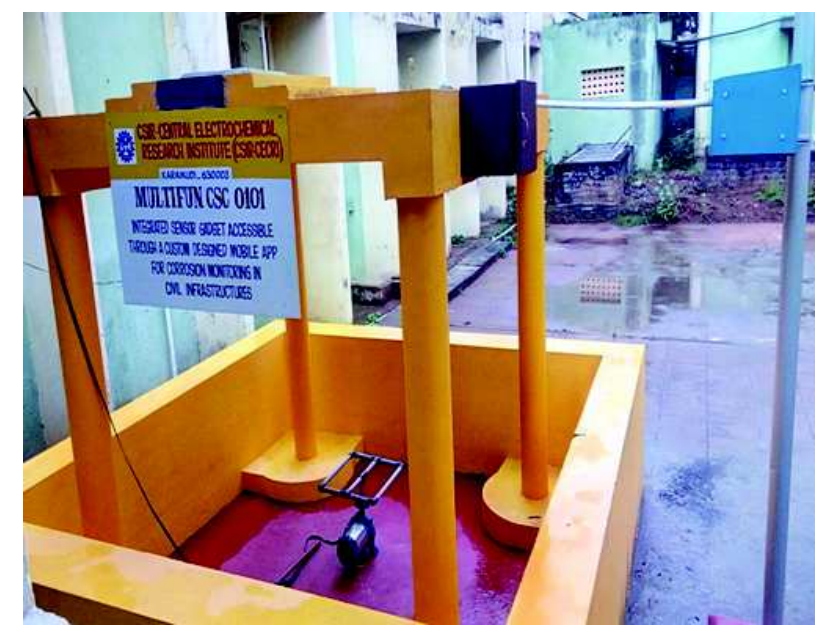

Fig. 4: Integrated corrosion monitoring sensor (ICMS) gadget accessible through a custom designed "MOBILE APP" for corrosion monitoring in civil infra structures, developed by CSIR-CECRI

improvements in primer technologies are getting introduced in the recent years. As an extension of electrochemical techniques for corrosion control, conditional survey of existing structures, evaluation of surface coatings for concrete and steel rebar, cathodic protection of sub-structures, repair and rehabilitation of corrosion-affected structures, ultilisation of waste product in construction, development of corrosion protective coatings for reinforcement bars, development of inhibitive systems for protection of rebars invite potential consultancy queries. Indigenous embeddable integrated corrosion sensor (to measure potential, corrosion rate and resistivity simultaneously) accessible through a MOBILE APP is the current development that provides access from anywhere and by any registered mobile app user. Green corrosion inhibitors for cooling water systems and triboluminescent (TL) coatings for the detection of crack and damage to prevent corrosion in high rise structures and bridges using an on-line monitoring kit, called SMART TL CAMERA is yet another recent advancement, wherein electrochemistry plays a key role (Saraswathi et al., 2016).

Researchers from IIT-Madras are working on the corrosion characteristics of high temperature oxidation and hot corrosion of Ni based superalloys and smart coatings for corrosion protection. Similarly, IIT-Kanpur is involved in preventing the corrosion of Al-Li alloys, advanced intermetallics (iron aluminides), coatings, composites, galvanic corrosion and the Delhi 
iron pillar. Further, researchers from IIT-Bombay deal with issues of corrosion due to oxidation and protective coatings, high temperature protective coatings (TBCs and EBCs), smart multi-functional coatings/composite coatings and novel corrosion inhibitor systems. In addition, IIT-Roorkee is also concentrating on the corrosion engineering, degradation behaviour of bulk and nanocrystalline coatings, corrosion protection of weldments and aqueous corrosion. IIT-Kharagpur research team is involved in designing new alloys with improved mechanical and corrosion properties. National Council for Cement and Building Materials conducts in-situ quality assessment, durability investigation and residual life assessment of concrete structures such as buildings, bridges, dams, power plants, chimney and silo. The investigations are generally followed by recommendations for repair and rehabilitation with state-of-the-art repair materials.

\section{Environmental Electrochemistry and Electro Remediation}

Environmental electrochemistry is one of the contemporary research areas, which in fact is the need of the hour, capable of addressing the mandatory requirements of reducing the concentration of polluting contaminants next to $\mathrm{CO}_{2}$ poisoning effect that poses alarming threats against the environment of the current scenario. Electrochemical treatment of various industrial effluents, decontamination of sludge with reference to heavy metals, development of methods for the removal of gaseous effluents, environmental impact assessment, safety audit and risk analysis and ground water pollution assessment are the research areas gaining attention amongst researchers. Several electrochemical approaches are being deployed for the treatment of industrial waste water, processed water or water rejects. The main objective in such cases is to remove the contaminants present in the effluents by combining advanced electrochemical remediation techniques and to realize the possibility of using the treated water for domestic applications. Of late, researchers are focusing on the design and development of desalination battery by using redox active polymers. i.e., the real time analysis has been made with sea water by means of effective removal of chloride ion along with the production of electricity.

National Environmental Engineering Institute (NEERI) has developed many innovative and environmentally sustainable electrochemical techniques that include Phytorid wastewater treatment technology to 15 MSME (Micro, Small and Medium Entrepreneurs) and solar electrolytic de-fluoridation technology of water to 9 MSME. Further, development of indigenous "Electronic Nose (e-nose)" by CSIRNEERI in association with C-DAC Kolkata has a potential to substitute imported "e-nose" (NEERI 2019). CSIR-NEERI's technology on iron removal has been installed at 66 locations by public health engineering department. A research group from IITMadras has developed the world's first nanochemistry based water filter for pesticide removal as many pesticides of relevance are halocarbons. The group has developed several technologies to remove other contaminants also from drinking water. Combining several such materials, an all-inclusive affordable drinking water purifier has been developed. This technology, named AMRIT, is being implemented now in the arsenic affected regions of India. Universities in India are concentrating on the research and development of electrochemical remediation using active charcoal as catalyst and adsorbent.

Under electro-remediation, of late, electrochemistry of carbon and electrochemical sequestration of $\mathrm{CO}_{2}$ attracts the attention of researchers due to the urgency for the effective management of carbon content in the atmosphere. Basically, utilization of carbon dioxide for the production of value added chemicals is a challenging task. Electrochemical reduction of carbon dioxide is one of the most promising techniques and accordingly many research groups in India are working towards the conversion of $\mathrm{CO}_{2}$ in to value added chemicals. For example, IISER Mohali has developed synthesis protocols for electricity-driven production of multicarbon chemicals and fuels from $\mathrm{CO}_{2}$ using microorganisms. Researchers from IIT Madras mainly focus on the development of suitable electrode/ electrolyte combination for efficient conversion of $\mathrm{CO}_{2}$. CSIR-CECRI has developed an electrochemical reactor with anode and cathode chambers separated by a composite perfluoro polymer cation exchange membrane, fabricated and used for the reduction of dissolved carbon dioxide under ambient conditions to formate. Currently, focus is given to develop metal free electrocatalysts for the electrochemical reduction of $\mathrm{CO}_{2}$ to make it as a viable technology. For example, doped graphene based electrocatalysts are used for 
the selective electrochemical reduction of $\mathrm{CO}_{2}$ to formate and metal organic framework based electrocatalyst for the highly selective reduction of $\mathrm{CO}_{2}$ to oxalic acid (Sreekanth et al., 2015; Senthilkumar et al., 2012) . Electrochemical reduction of aromatic ketones in non-aqueous solvents containing carbon dioxide $\left(\mathrm{CO}_{2}\right)$ has been extensively studied as a strategic route for the synthesis of hydroxy carboxylic acids (which are important intermediates in the production of non-steroidal antiinflammatory drugs) by electrocarboxylation route.

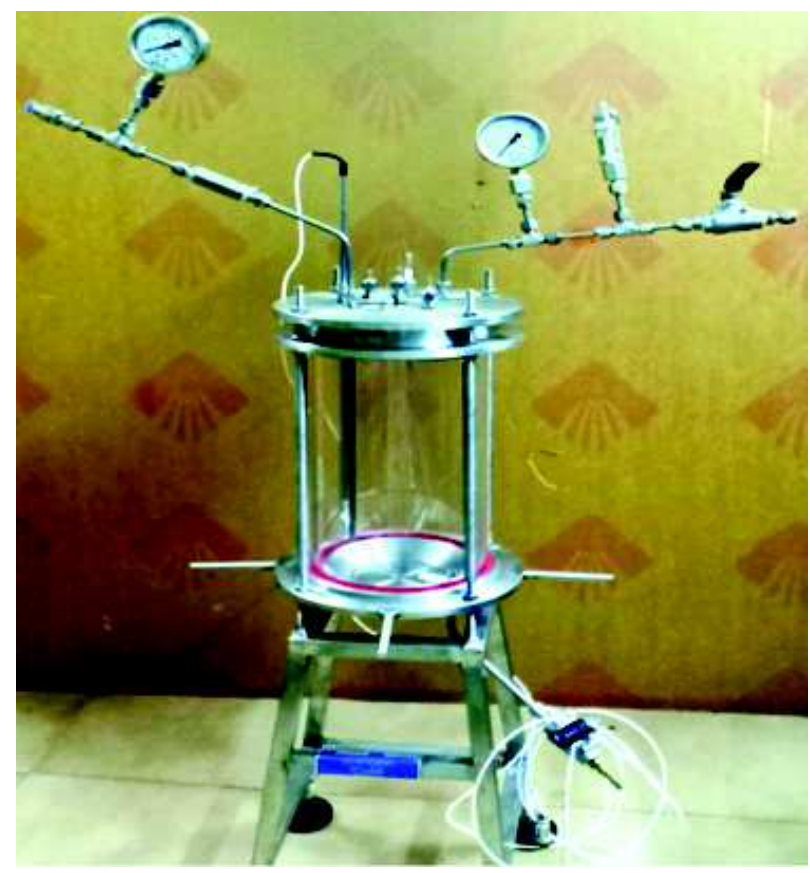

Fig. 5: Custom designed $\mathrm{CO}_{2}$ reactor for the synthesis of value added chemicals

\section{Electroplating and Metal Finishing}

Current Indian plating industry has the potential to provide technological solutions by providing and delivering innovative, custom made and environment friendly products. Among the various CSIR labs, CSIR-CECRI and national Aerospace Laboratory (NAL) are the pioneering institutes involved in the development of electroplating, pulse deposition and metal finishing technology (EMFT) in India. For example, technology on modern electroplating of trivalent chromium and hard chrome, technology for electroplating of gold, silver, rare earth metals, refractory metals and alloys, anodizing and hard anodizing, lead free plating, barrel electropolishing, electropolishing, brush plating, electroless plating, cyanide-free electroplating baths, self-assembled monolayer (SAMs) coatings, electroforming technology and 3D-printing for metals and alloys are the focus research areas as on date. Besides the brass cluster activities, technical and consultancy services offered by CSIR and CECRI in particular to various Indian industries regarding the electroless nickel on beryllium rings and discs for space mirrors, on textile aluminium drums, on marraging steel LCA (Light Combat Air-craft) components for Aeronautical Development Agency (ADA), on alumina ceramic rods for electronic resistors need a special mention. IIT-Hyderabad is focusing on the development of novel alloys and metals with enhanced properties using electrodeposition technique. Other than research institutes, there are thousands of job-work electroplating units operating in various parts of the country. For example, the following states do contain a large number of electroplating units: Andhra Pradesh-Hyderabad, Delhi, Gujarat-Ahmedabad, Haryana-Faridabad, Karnataka-Bengaluru, Maharashtra-Mumbai, Pune, Nasik, Punjab-Ludhiana, Tamil Nadu-Chennai, Madurai and Uttar PradeshNOIDA. Further, Metal Finishers' Association of India (MFAI) is started to provide a common forum for metal finishers, Industrialists, designers and professionals to meet and foster the advancement of surface engineering, with particular focus on science of electroplating technology in India.

\section{Electro-organic Synthesis}

Electrochemistry is known to be one of the resourceful techniques that can be adopted to synthesize a range of chemical compounds. In simple terms, electrons are better alternates to replace toxic and expensive chemical reagents. In electrochemical synthesis, formation of undesirable wastes can be prevented and the reaction can be stopped at any moment by simply cutting the power supply. In short, electrochemical synthesis protocols offer an environment friendly technology with unique selectivity towards oxidation, reduction and functionalization. Processes commercialized using electrochemical synthesis include amino guanidine bicarbonate, unsymmetrical dimethyl hydrazine, calcium gluconate and potassium iodate (Cardoso et al., 2017). Electrochemical fluorination and selective fluorination effectively participate in the design of protocols for 
the electrosynthesis of fine chemicals. Research institutions including CSIR and IITs are developing process knowhow and technological solutions for various electro-organic syntheses such as anodic functionalization of organic compounds, cathodic conversion of organic compounds, electrogenerated acids, electrogenerated bases, ionic liquids (ILs) and indirect electrosynthesis. In addition, adiponitrile, substituted benzaldehydes, anthraquinone, fluorinated products and succinic acid are synthesized with high yield using custom designed electro organic synthesis route and the technology is being implemented by many industries.

\section{Miscellaneous Activities}

In addition to the discussed areas of electrochemical research, earlier CECRI had played a major role in the extraction of strategically important metals like sodium, calcium, magnesium, aluminium and titanium by electro winning and refining processes. Similarly, transition and rare earth metals, alloys and compounds such as novel oxides, borides, carbides, and nitrides are also being prepared by electrometallurgical routes. As an extension, advanced nanomaterials have also been developed for high temperature oxidation and wear resistance coatings, which are used in missile and defense applications. Electro-refining of lead from smelted lead acid battery scrap, electrolytic manganese dioxide for batteries, regeneration of spent etchant of PCB industries with simultaneous recovery of copper, recovery of silver from photographic spent solution, electrolytic preparation of sulphur depolarized nickel and recovery of gallium by amalgamation and ion exchange technique are few other challenges addressed using electrochemical techniques. CSIR laboratories, Baba Atomic Research centre (BARC) and Indira Gandhi Centre for Advanced Research (IGCAR) are being involved in the development of strategic sector related technologies.

Apart from all the mentioned research progress being accomplished in the field of electrochemistry, registered professional societies/organizations (nongovernment) in India like SAEST (Society for advancement of electrochemical science and technology), NCCI (National corrosion council of India), ECS (Electrochemical society, India chapter) and ILZDA (India lead zinc development association) are contributing enormously to disseminate the meritorious and greener possibilities lying with electrochemical approaches to solve a wide variety of societal issues. In particular, these societies provide a common platform for industrialists, technologists, scientists and others to meet and foster the advancement of electrochemistry, electrochemical technology and allied fields. Table 3 accordingly illustrates the role of such professional associations in promoting electrochemical research in India and showcasing indigenous technologies in the global arena.

Table 3: Professional societies/forums/councils in India associated with electrochemical research

\begin{tabular}{|c|c|}
\hline Organizations & Role \\
\hline $\begin{array}{l}\text { SAEST (Society for the } \\
\text { Advancement of }\end{array}$ & \multirow{2}{*}{$\begin{array}{l}\text { Society that facilitates } \\
\text { dissemination of fundamental and } \\
\text { applied electrochemical research } \\
\text { through conferences, } \\
\text { brainstorming sessions and } \\
\text { workshops apart from training } \\
\text { offered to Indian electrochemical } \\
\text { industries }\end{array}$} \\
\hline $\begin{array}{l}\text { Electrochemical Science \& } \\
\text { Technology) }\end{array}$ & \\
\hline $\begin{array}{l}\text { ECSI (Electrochemical } \\
\text { Society of India) }\end{array}$ & $\begin{array}{l}\text { Electrochemical Society of India } \\
\text { is a Bangalore based organization } \\
\text { for similar objectives }\end{array}$ \\
\hline $\begin{array}{l}\text { NCCI (National corrosion } \\
\text { Council of India) }\end{array}$ & \multirow{2}{*}{$\begin{array}{l}\text { Forum for corrosion related } \\
\text { business bodies, entrepreneurs, } \\
\text { researchers and academia to } \\
\text { exchange ideas and strengthen } \\
\text { collaboration }\end{array}$} \\
\hline $\begin{array}{l}\text { ECS (Electrochemical } \\
\text { Society, US) India- Chapter) }\end{array}$ & \\
\hline \multirow[t]{2}{*}{$\begin{array}{l}\text { NACE (National } \\
\text { Association of Corrosion } \\
\text { Engineers) India Chapter }\end{array}$} & $\begin{array}{l}\text { Synonymous to overseas society } \\
\text { chapters, organizes conferences, } \\
\text { winter school lectures and } \\
\text { brainstorming sessions on hot core } \\
\text { areas }\end{array}$ \\
\hline & $\begin{array}{l}\text { High end business body that } \\
\text { promotes corrosion mitigation } \\
\text { related business amongst } \\
\text { industries and strategic sector apart } \\
\text { from strengthening }\end{array}$ \\
\hline
\end{tabular}

\section{Conclusions}

Despite rapid progress being realized in recent times in molecular tailoring of electrode surfaces, monolayer electrocatalysts, layer-by-layer design of graded composition and core-shell structures, many existing green materials currently used are either inferior or comparable with the conventional materials in terms of their efficiency and durability, and hence many more robust electrode materials are needed for high- 
performance electrochemical devices. Development of energy storage materials capable of surviving extreme environmental physical conditions is another hot area of research, because, space missions require the development of such high or low temperature and/ or pressure supercapacitors and batteries. Hence innovative electrodes and electrolyte are needed to be designed and developed for these devices using concepts borrowed from Artificial Intelligence. Research on transparent and flexible energy storage devices is another thrust area, where electrode material, geometry etc. are the vital factors. Discovery of ultra-thin layers could really make a breakthrough in these efforts. However, issues like scalability and production cost are to be addressed, prior to commercialization. Another important area of research is that non-metallic electrodes are highly demanding not only in energy storage devices but in all other fields including electrochemical activities such as ORR, catalysis etc. This can make a dramatic change in device weight and hence can lead to light weight devices.

In general, electrode optimization, active material development and electrolyte designing are needed to make these newer concepts to reality. Recent trends in materials science, forced by the global pollution issues and global economy crisis, rely on eco-efficient materials for new generation technologies. Similarly, newer concepts need to be launched to bring the device fabrication out of the high-end clean room facilities. Revolutionary concept like 3D device printing is successfully attempted by the researchers for 3D electrode development and the active research on this aspect is to get translated as a technology in the near future. Moreover, inkdevelopment for these 3D printing will be a hot area of research in the near future. Another major research

\section{References}

Anantharaj S, Ede S R, Karthick K, Sam Sankar S, Sangeetha K, Karthik P E and Kundu S (2018) Precision and correctness in the evaluation of electrocatalytic water splitting: Revisiting activity parameters with a critical assessment Energy Environ Sci 11 744-771

Bard A J and Faulkner L R (2000) Electrochemical Methods: Fundamentals and Applications $2^{\text {nd }}$ Edition, 1-864

Cardoso D S P, Šljukiæ B, Santos D M F and Sequeira C A C area that needs attention and should occur immediately is the development of sensing electrodes, otherwise called as the universal sensor for various bio analytes. The development of nanoelectrodes and related electrochemistry can unravel a lot of information in this direction. Similarly, interaction between bio molecules and nanoparticles (nano-building blocks) is becoming an active research area, to identify new bio-markers/trackers and new therapy agents and drug carriers. Above all, food safety is a global health goal and the food borne diseases are major health threats and so it becomes essential to monitor the presence of pathogens at every step during the food production, processing and storage. For a rapid screening and to check the quality of the food commodities some highly sensitive detection methods such as electrochemical platform for multiplexed detection of food borne pathogens is essential.

The aforesaid progress in terms of materials development associated with the understanding and demonstration of related electrochemical technique would lead to many ground breaking technological outcomes, provided consistent support in terms of scientific and financial aspects is rendered to this privileged electrochemical research community. The main challenge of qualifying the electrochemical techniques as economically viable protocols needs to be addressed by the researchers globally, wherein indigenous innovations, if succeeded would bring in global IPR as well.

\section{Acknowledgements}

The authors thank DST-MES for financial support through GAP 16/17 project. Dr. Saravanan Karuppiah is thanked for his assistance in designing the content of this communication.

(2017) Organic Electrosynthesis: From Laboratorial Practice to Industrial Applications Org Process Res Dev 21 1213-1226

Gladysz J and Michel J (1990) Electrochemistry - An Introduction Chem Rev 90 689-689

Manohar Venkat M, Varghese George V, Egnaraman Venkatraman Y, Phani K L N and Mathiyarasu J (2010) Non-enzymatic electrochemical method for simultaneous determination of total hemoglobin and glycated hemoglobin US patent 
number US2010089774-A1 dt. 15.04.2010; International patent (PCT) number WO2010043985-A1 dt. 22.04.2010

MNRE Report on fuel cell development (2016) Ministry of New and Renewable Energy Government of India, New Delhi, June

NEERI 2019 Website of CSIR-National Environmental Engineering Research Institute (http://www.neeri.res.in/ accessed in March 2019)

O'Regan B and Grätzel M (1991) A low-cost, high-efficiency solar cell based on dye-sensitized colloidal $\mathrm{TiO} 2$ films Nature 353 737-740

Raju C V and Kumar S S (2017) Highly sensitive novel cathodic electrochemiluminescence of tris (2,22 -bipyridine) ruthenium(II) using glutathione as a co-reactant Chem Commun 53 6593-6596

Sahasrabudhe A, Dixit H, Majee R and Bhattacharyya S (2018) Value added transformation of ubiquitous substrates into highly efficient and flexible electrodes for water splitting Nat Commun 9 1-14

Sampath S, Sarma D D and Shukla A K (2016) Electrochemical Energy Storage: The Indian Scenario ACS Energy Lett 1 1162-1164
Saraswathy V, Manoharan S P, Muralidharan S and Mayandi M (2016) Development of Mobile Platform using integrated Sensor Gadget for Corrosion Monitoring in Civil Infrastructures Indian Patent 0215 NF2016

Senthil Kumar R, Senthil Kumar S and Anbu Kulandainathan M (2012) Highly selective electrochemical reduction of carbon dioxide using $\mathrm{Cu}$ based metal organic framework as an electrocatalyst Electrochem Commun 25 70-73

Sreekanth N, Nazrulla MA, Vineesh T V, Sailaja K V and Phani K L N (2015) Metal-free boron-doped graphene for selective electroreduction of carbon dioxide to formic acid/formate Chem Commun 51 6061-16064

Swarnkar A, Marshall A R, Sanehira A M, Chernomordik B D, Moore D T, Christians J A, Chakrabarti T and Luther J M (2016) Quantum dot-induced phase stabilization of $\alpha$ $\mathrm{CsPb}_{3}$ perovskite for high-efficiency photovoltaics Science 354 92-95

Uslu B, Aboul-Enein H Y and Ozkan S A (2011) International Journal of Electrochemistry, Modern Analytical Electrochemistry: Fundamentals, Experimental Techniques, and Applications 2011 196906-08. 